\title{
Application and Participation of Artificial Intelligence in Agriculture
}

\author{
Anu Bhadu \\ Department of Mathematics, Chandigarh University, Gharuan, Mohali, Punjab \\ Email: anubhadu180@gmail.com
}

\begin{abstract}
This study provides a detailed review of the literature on the use of artificial intelligence in agriculture. Agriculture has numerous obstacles, including disease, incorrect soil management, drainage, and irrigation, among others...

By this due to catastrophic crop loss and environmental threats chemical excessiveness. Many researchers have been concluded to address these issues. With its learning capabilities, artificial intelligence has become a vital approach for solving various agricultural difficulties. Systems are being created to aid agricultural specialists around the world in finding better answers. It covers 100 important contributions where the challenges related to agriculture are encountered by artificial intelligence techniques. Readers will be able to see how agriculture has changed in many ways through (1983 to 2017) 34 years.
\end{abstract}

\section{KEYWORDS -}

Management of crop; Pest management; Treatment of diseases;monitoring and storage of agricultural products; Management of soil and irrigation; Management of weeds

\section{INTRODUCTION}

$\mathrm{Al}$ is one of the key areas research in computer science. Its quick development techniques and application that covers a large area. As a result of robotics applicability when there are problems that can't be solved by traditional computing structure in addition humans.Approximately 30.7 percent of the population is directly involved in $\mathbf{2 7 8 2}$ million hectares of land used for agriculture. There is no smooth operation venture as it confronts from sowing until harvesting, there are a lot of obstacles to overcome. Pest and disease infestation, weed control, yield prediction, improper drainage and irrigation etc...are biggest problems which occurs.

In 1983, the first mention of computers in agriculture was made.To solve existing problems in agriculture different approaches are suggestedstarting with databases and ending with decision-making aids. In terms of accuracy and robustness, Al-based systems have shown to be the best performers among these options.

We were only able to catch the specifics of each and every one of them thanks to Al technology and every situation and gave solution which fits best for that particular problem. With the development of various Al techniques very complex problems are being solved gradually.

\section{MANAGEMENT OF CROP}

Generally, a user interface for crop management are provided for crops overall management covering each aspect of farming. Idea of usage of Al technique was proposed firstly by Lemmon and McKinnon in 1985 in their paper "Expert Systems for Agriculture". Stone and Toman came up with an expert system POMME for apple plantation management.

Robinson and Mort concocted a multifaceted feed forward counterfeit neural organization based framework to shield citrus crops from ice harm on the Italian island of Sicily. To prepare and assess the organization, the info and yield boundaries were coded in double structure. The creators explored different avenues regarding different info designs to track down the most dependable model.With two output groups and six inputs, the best model found so far had a 94 percent accuracy. Li, S. K. et al. proposed an image-based Al technique for wheat crop, which used an algorithm for pixel labelling, and 
then a Laplace transformation to improve picture details. The finest arrange gotten had five covered up layers that had been trained for 300000 iterations and had an average exactness of $85.9 \%$.

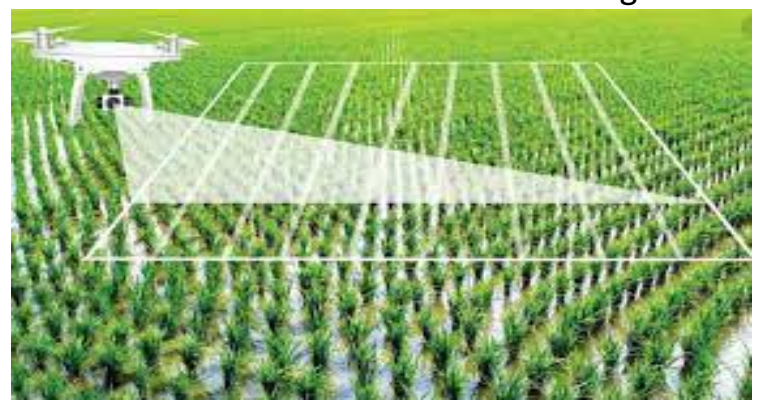

\section{PEST MANAGEMENT}

Fig 1. Crop managing

One of the major problem in agriculture which results in significant economy misfortune is Insect pest infestation. Over decades analysts haveattempted to moderate this threat by improvement of computerized frameworks that may distinguish the dynamic bothers and propose control measures. Since the data which goes to agriculture management is often incomplete, ambiguous, in addition imprecise, the expert system built on rules can cause confusion. Several Fuzzy logic based expert systems have been proposed to capture this complexity, including Saint et al., Siraj and Arabia, Peixoto et al., IPEST by Hayo et al., Roussel et al., Shi et al., and Jesus et al. Ghosh et al. created TEAPEST, an master system for bug control in tea, by using an object-oriented approach to frame a rule base. A step by step identification and the discussion procedure has also been implemented in this case.Later, using a diverse back spread neural organization,Samanta as well as Ghosh revamped the device, and Banerjee et al. reformulated it using radial.

\section{$\rightarrow$ ROUTE OPTIMIZATION}

Many pest control companies have grasped the importance of an automated route planning engine, which was once a painstakingly manual procedure. Route optimization software isn't meant to take the position of humans, who frequently have valuable domain knowledge and local expertise, but rather to automate the most time-consuming and complex components of routing so that employees can focus on more important tasks.

\section{$\rightarrow$ DRONES}

Drones are being considered by a small but rising number of pest control companies. Inspect-All Services, a technology innovator in the business, was one of the first organizations in the country to offer professional drone home inspections. Before providing their first paid drone inspection, Brian Lunsford, Co-owner and President of Inspect-All, says there was a lot of planning ahead of time.

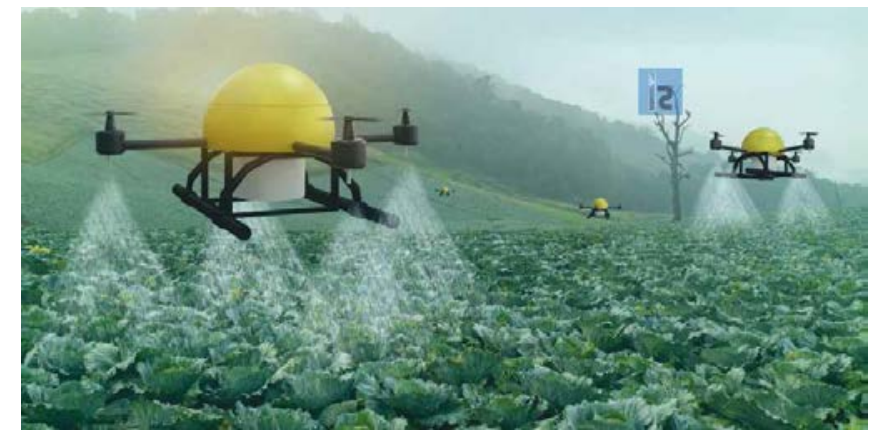

Fig 2. Drones 


\section{$\rightarrow$ LEAD MANAGEMENT AND MARKETING AUTOMATION}

For most organizations, including pest control, generating cost-effective leads is a constant issue. Converting leads to clients effectively (and efficiently) can be even more difficult, especially for small and medium-sized firms without a dedicated sales force. Sales and marketing automation, for example, can send out emails to nurture indecisive leads, enhance conversion rates through workflow automation, and guarantee that no good leads "fall between the cracks."

Artificial intelligence is both an exciting and frightening topic in business, as the idea of "bots" replacing humans in the workforce is becoming an increasing a problem. For now, the concept that Al will be able to replace people in a service-oriented sector like pest treatment is a long shot.

\section{TREATMENT OF DISEASES}

Plant infections are one of the most common causes of plant and crop death. Farmers can overcome and treat diseases more effectively if they are detected early. Expert systems are extremely useful in diagnosing ailments and describing therapy options.

The development of a visual method for distinguishing between crop seedlings and weeds is a crucial step toward automating non-chemical weed management systems in agriculture and reducing chemical use through spot spraying. Many factors put food security at jeopardy. Droughts are a result of climate fluctuation in some areas, making important resources scarce. Political unrest in other areas causes logistical problems for cultivating, harvesting, and shipping produce. Plant disease, on the other hand, may wipe out entire crops with little notice almost anywhere.

Next year, it expects to begin deploying its software on drones, agricultural equipment, and greenhouses, allowing farmers to automate the process and respond to crop diseases more swiftly. For the time being, it's focusing on gathering photos and learning how to reliably identify as many crop diseases as possible, with a concentration on important crops like maize and wheat, which are planted by large-scale farmers all over the world.Users of Plantix receive actionable information in exchange for contributing images, such as disease scientific names, triggers, symptoms, treatment choices, preventativeassesses, and so on. This is a real green real revolution.

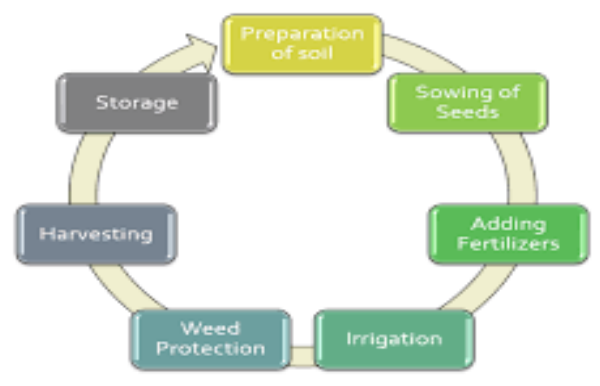

Fig 3. Revolution cycle

\section{MONITORING SYSTEM FOR SOIL AND HARVEST WELL-BEING:-}

The kind of soil and the supplements within the soil impact the sort of edit planted and the quality of the create. Soil quality is breaking down as a resultincreased deforestation, which is problematic,making it difficult to identify the situation of the soil. A startup in the technology field established in Germany PEAT has createdPlantix, an Al-based application that can distinguish supplement shortages in soil, as well as plant bothers and maladies, and allow ranchers exhortation on how to utilize fertilizer to extend gather quality. Image recognition technology is used in this app. Smartphones can be used by the farmer to photograph plants. 


\section{MANAGEMENT OF SOIL AND IRRIGATION}

In agriculture, soil and irrigation management are extremely important. Destitute water systems and soil administration induce trim hardship and quality degradation. This segment highlights some soil and irrigation management research that has been aided by artificial intelligence strategies. Brats et al. developed a set of rules with master system to evaluate the plan and proficiency of smaller scale water system frameworks.Arif et al. developed a framework based on fictitious neural networks for estimatingpaddy soil wetness. Broner and Comstock are two other popular artificial neural networkbased soil and irrigation systems. Using four atmospheric inputs, for precipitation forecast, Manek and Singh compared different neural organize topologies. This research discovered that radial basis function neural networks are more effective than other types of neural networks.

$\rightarrow$ In a single year, the agricultural division uses 85 percent of the world's available freshwater resources. And this pace is rapidly increasing in tandem with population growth and rising food demand.

$\rightarrow$ The diverse water system strategies with the essential thought process of creating a framework with decreased asset utilization and expanded efficiency.

\section{ADMINISTRATION OF WEEDS}

Herbicide utilize includes a synergistic impact on both human wellbeing and the environment. Through weeding with care and precision management, modern Al methods are being used to reduce herbicide application. Pasqual created a set of rules for weed detection in addition ofcrops expulsion such aswheat, oats, barley, triticale, and other grains.To identify weeds of five different species, researchers utilised machine vision and a neuronal setup that is primed for back proliferation. With the same $t$ of inputs as in the previous paper,Burks and colleagues compared three different neuronal arrangement models, primarily back engendering, counter-proliferation, and widespread work-based premise modelsand found that the back propagation network performs best with 97 percent accuracy.Shi et al. developed another method that combined picture investigation and neural systems. Other factors that Whirlpool et al. Nebot et al., and Barrero et al. discussed were outstanding.

\section{APPLICATIONS:-}

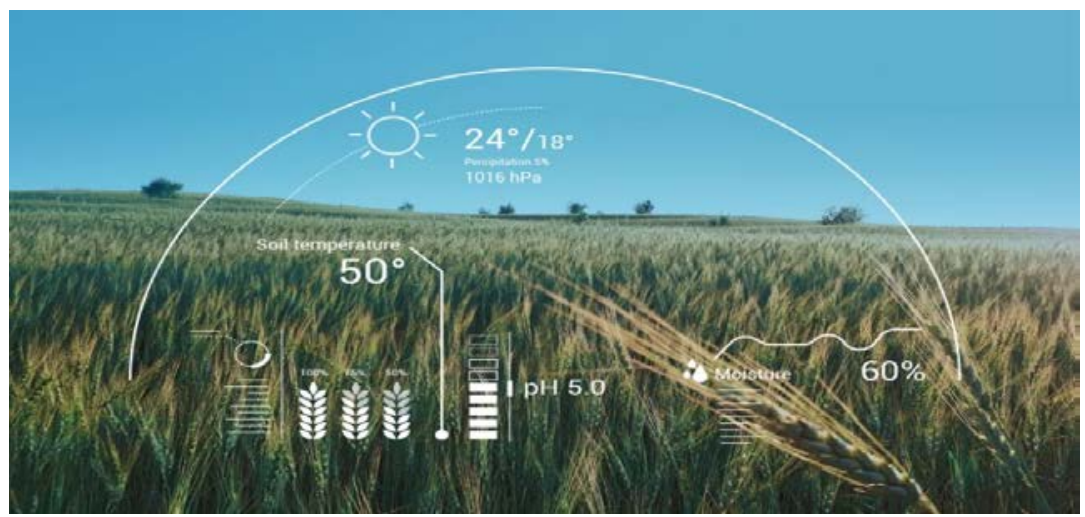

Fig 4. Forecasting

1. Use of weather forecasting:- Farmers are finding it difficult to determine the best time to sow seed as climatic conditions change and pollution rises. Agriculturists can use Manufactured Insights to help them make better decisions and can analyze climate conditions using climate 
forecasting, allowing them to plan the type of crop that can be grown and when seeds should be sowed.

2. Robotics:- Artificial intelligence (AI) is being used to construct farming regions where Robots can do several duties. In comparison to people, this sort of robot is prepared to stifle weeds and collect crops at a speedier rate with greater volumes. Agricultural labour faces challenges that can bargain by the robots.

3. Pest-detection software:- Bothers(Pest) are one of the foremost damaging adversaries of farmers' crops.To make a decision, Al frameworks examine adherent photographs and compare them to previous data whether any creepy crawlies have landed and, on the off chance that so, what species of creepy crawly has landed (grasshopper, grasshopper, etc.).Also, give out alerts to the smart-phones of farmers so that they can take the necessary precautions and make use of the necessary creepy crawly management.

\section{FINAL RESULTS : -}

This study examines thatin the discipline of $\mathrm{Al}$, there have been 100 research papers published, applications in agriculture between 1983 and 2017, spanning 34 years. There are far too many works to mention in this limited space. To cover the multidimensional approaches, only a few representatives are chosen to be addressed. This material has been written to be as educational as possible,considering the nuances of the many Al methods used in agribusiness. Rule-based expert systems were widely used in the early 1980s and 1990s, however, after 1990, phony neural organizing models and airy deduction frameworks have taken over. Within the final few a long time, there has been an increment within the utilize of cross breed frameworks such as neuro-financial frameworks.It advances toward more computerized, exact, and real-time frameworks.More research is being carried oututilizing more advanced instruments, so that traditional farming can continue to existlow-cost shift to precision agriculture.

\section{REFERENCES :-}

1. "Artificial intelligence," by E. Rich and Kevin Knight, McGraw-Hill, New Delhi, 1991.

2. GOSSYM: A simulator of cotton crop growth and yield, Technical bulletin, Agricultural Experiment Station, South Carolina, USA, 1983. D.N. Baker, J.R. Lambert, J.M. McKinion, GOSSYM: A simulator of cotton crop growth and yield, Technical bulletin, Agricultural Experiment Station, South Carolina, USA, 1983.

3. "Expert systems for agriculture," Computers and Electronics in Agriculture, vol. 1 no. 1, pp. 31-40, 1985. J. M. McKinion and H. E. Lemmon, "Expert systems for agriculture," Computers and Electronics in Agriculture, vol. 1 no. 1, pp. 31-40, 1985.

4. "A neural network device for the defense of citrus crops from frost damage," by C. Robinson and N. Mort. 177-187 in Computers and Electronics in Agriculture, vol. 16 no. 3, 1997.

5. EXPERT SYSTEM OF NON-POLLUTION FEICHENG PEACH PRODUCTION IN CHINA, M. Li, Y. Wang, L. Wang, Z. Yan, Q. Yu. Agricultural Computer and Computing Technologies, Vol. 2, pp. 1371-1374, 2002.

6.https://insights.workwave.com/industry/pest-control/the-future-of-artificial-intelligence-in-pestcontrol/

7.https://www.google.com/url?sa=i\&url=https\%3A\%2F\%2Fwww.analyticsvidhya.com\%2Fblog\%2F2020 $\% 2 \mathrm{~F} 11 \% 2 \mathrm{Fartificial-intelligence-in-agriculture-using-modern-day-ai-to-solve-traditional-farming-}$ problems\%2F\&psig=AOvVaw22LHphulOuz75DAzO4wfyD\&ust $=1626533728758000 \&$ source $=$ images $\& c d=$ vfe\&ved=0CAsQjRxqFwoTCPiS9bzs5_ECFQAAAAAdAAAAABAD 
8.https://www.google.com/url?sa=i\&url=https\%3A\%2F\%2Fwww.analyticsvidhya.com\%2Fblog\%2F2020 $\% 2 \mathrm{~F} 11 \% 2 \mathrm{Fartificial}$-intelligence-in-agriculture-using-modern-day-ai-to-solve-traditional-farmingproblems\%2F\&psig=AOvVaw22LHphul0uz75DAzO4wfyD\&ust=1626533728758000\&source=images\&cd= vfe\&ved=0CAsQjRxqFwoTCPiS9bzs5_ECFQAAAAAdAAAAABAJ

9.https://www.google.com/url?sa=i\&url=https\%3A\%2F\%2Fwww.analyticsvidhya.com\%2Fblog\%2F2020 $\% 2 \mathrm{~F} 11 \% 2 \mathrm{Fartificial-intelligence-in-agriculture-using-modern-day-ai-to-solve-traditional-farming-}$ problems\%2F\&psig=AOvVaw3EtPBZfrA-

KXTtl1wdlThp\&ust=1626534717089000\&source=images\&cd=vfe\&ved=0CAsQjRxqFwoTCOivz5Xw5_ECF QAAAAAdAAAAABAD 